\title{
INVESTIGAÇÃO MATEMÁTICA COMO RECURSO METODOLÓGICO PARA O ENSINO DE GEOMETRIA NOS ANOS INICIAIS
}

\section{Mathematical Investigation as a methodological resource for the Teaching of geometry in the early years}

\author{
Andressa Franco Vargas (andressavargas1@yahoo.com.br) \\ Universidade Franciscana - UFN \\ José Carlos Pinto Leivas (leivasjc@yahoo.com.br) \\ Universidade Franciscana - UFN \\ Débora da Silva de Lara (dd.lara@ hotmail.com) \\ Instituto Federal Farroupilha Campus Alegrete
}

Resumo: O presente trabalho teve por objetivo explorar percepção, visualização e construção de conhecimentos geométricos por meio de atividades lúdicas voltadas ao $4^{\circ}$ ano do Ensino Fundamental tendo como parâmetro, para tal, a Base Nacional Comum Curricular (BNCC). O estudo elenca possibilidades para melhorar a aprendizagem de Matemática, auxiliando professores e estimulando a participação dos alunos durante as aulas. Para isso, baseou-se na metodologia da Investigação Matemática, por meio da qual foram desenvolvidas atividades que contemplassem os conteúdos de "direção", "sentido" e "paralelismo", os quais constam na BNCC para o $4^{\circ}$ ano do Ensino Fundamental. Desse modo, a pesquisa foi desenvolvida em dois momentos, o primeiro, com o mapa de uma cidade e questões norteadoras para que os alunos discutissem e se localizassem como parte do espaço apresentado; o segundo, com a aplicação do jogo "Na direção Certa", abordando questões topológicas, a fim de contribuir com o desenvolvimento das noções de "localização e movimento". Conclui-se a partir disso que, as atividades desenvolvidas contemplaram as habilidades descritas na BNCC, pois os resultados permitiram a visualização das diversas estratégias e métodos para solucionar os problemas abordados, de modo que os alunos conseguiram explorar trajetos, considerando os conceitos iniciais de direção, sentido e paralelismo.

Palavras-chave: Geometria; Anos Iniciais; BNCC; Ensino Fundamental.

Abstract: The present work aimed to explore perception, visualization and construction of geometric knowledge through playful activities aimed at the 4th grade of Elementary School, having as its parameter, the Common National Curriculum Base (BNCC). The study outlines possibilities for improving mathematics learning by assisting teachers and stimulating student participation while performing a task in the classroom. For this, it was based on the methodology of Mathematical Research, through which activities

${ }^{1}$ O presente trabalho foi realizado com apoio da Coordenação de Aperfeiçoamento de Pessoal de Nível Superior - Brasil (CAPES) - Código de Financiamento 001. 
were developed that contemplated the contents of "direction", "sense" and "parallelism", which are included in BNCC for the 4th year of elementary school. Thus, the research was developed in two moments, namely: the first moment, with the map of a city and some guiding questions for students to discuss and locate themselves as part of the presented space; the second moment, with the application of the game "In the Right Direction", addressing topological questions, in order to contribute to the development of the notions of "location and movement". It is concluded from this that the activities developed contemplated the skills described in the BNCC, because the results allowed the visualization of the various strategies and methods to solve the problems addressed, so that the students were able to explore routes, considering the initial concepts of direction, sense and parallelism.

Keywords: Geometry; Early Years; BNCC; Elementary School.

\section{INTRODUÇÃO}

O presente artigo representa o trabalho final de uma disciplina pertencente a um Programa de Pós-Graduação em Ensino de Ciências e Matemática de uma universidade do estado do Rio Grande do Sul. Tal disciplina tem como objetivos: a) Analisar o papel da Matemática na formação de professores dos Anos Iniciais; b) Fortalecer a Educação Matemática como campo de conhecimento capaz de selecionar e articular o conteúdo desse nível de escolaridade com estratégias de ensino; e c) Organizar o trabalho pedagógico por meio de recursos didáticos pertinentes. Para concretizar tais objetivos, são desenvolvidas aulas expositivas dialogadas com atividades concretas que fomentam a aquisição dos conteúdos programáticos, bem como exploradas a Teoria dos Registros de Representação Semióticas, a Resolução de Problemas, Jogos e a Investigação Matemática. $^{2}$

Com base nas discussões acerca da Base Nacional Comum Curricular (BNCC) (BRASIL, 2017), bem como nas contribuições e aversões que essa possa fornecer, foi escolhido, pelos dois primeiros autores do artigo, o eixo GEOMETRIA como tema central deste trabalho. De acordo com a BNCC, no que tange especificamente ao ensino de Geometria, objetos de conhecimento voltados à localização e à movimentação incluem pontos de referência, direção, sentido, paralelismo e perpendicularismo. O que se espera de um aluno, de acordo com o referido documento, é que ele consiga descrever deslocamentos e localizar pessoas e objetos no espaço, por meio de malhas

${ }^{2}$ Os objetivos da disciplina não possuem domínio público, uma vez que são disponibilizados somente via sistema para alunos matriculados na mesma. 
quadriculadas e representações como desenhos, mapas, plantas baixas e croquis. Além disso, é desejável que ele seja capaz de empregar termos como "direita" e "esquerda", mudanças de direção e sentido, intersecções, transversais, paralelas e perpendiculares.

O eixo Geometria foi escolhido a partir da constatação de que esta, por vezes, acaba por ser esquecida pelos professores, por razões de falta de tempo ou pela opção por conteúdos como Álgebra e Aritmética, conforme cita Lorenzato (1995), quando mesmo diz que muitos professores não tem conhecimento necessário para ensinar Geometria, o que acarreta em uma valorização exagerada nestas outras duas áreas, e alegam que isso se deve a falta de tempo. Contudo, o especificado tópico assume grande importância para a alfabetização matemática de alunos dos Anos Iniciais, pois é necessário que estes desenvolvam capacidades de se localizar no espaço, manipular e construir objetos, além de desenvolver raciocínio matemático.

A investigação objeto deste artigo teve como objetivo explorar a percepção, visualização e construção de conhecimentos geométricos por meio de atividades lúdicas voltadas ao $4^{\circ}$ ano do Ensino Fundamental. Buscou-se, como objetivos específicos: a) Averiguar se as atividades contemplam habilidades descritas na BNCC para tal eixo; e b) Desenvolver ou iniciar um pensamento geométrico por parte dos alunos. Assim, espera-se que os resultados obtidos com a investigação possam contribuir para o ensino de Matemática nos Anos Iniciais, bem como subsidiar professores e pesquisadores na busca de alternativas para a inclusão de conteúdos e conceitos relacionados aos eixos temáticos apresentados no supracitado documento.

Tendo em vista essa contextualização inicial, o artigo está organizado da seguinte forma: No primeiro momento, são feitas considerações sobre o Ensino de Geometria nos Anos Iniciais, bem como um breve mapeamento de dissertações que abordam o tema "Geometria e BNCC". Posteriormente, apresentamos um referencial sobre a metodologia da Investigação Matemática, e em sequência as atividades elaboradas para a aplicação. Por fim, são expostas as análises e conclusões obtidas após a realização da proposta com o grupo de alunos.

\section{PRESSUPOSTOS TEÓRICOS}




\title{
2.1 O ENSINO DE GEOMETRIA NOS ANOS INICIAIS
}

O Ensino de Geometria nos Anos Iniciais ocorre formalmente pela primeira vez no âmbito escolar no $4^{\circ}$ ano do Ensino Fundamental. É desejável que as atividades introdutórias ao tema despertem o vislumbre dos estudantes, cabendo ao professor chamar a atenção para o ensino de Geometria como algo interessante e que possa fazer parte do seu quotidiano. Os jogos são envolventes para o aluno e, por isso, o educador pode utilizá-los para explorar o conteúdo de Geometria, levando em consideração que

a geometria está presente à nossa volta, no mundo que nos cerca, porém, muitas vezes não a percebemos, ela representou nossa janela descoberta. Com "a abertura dessa janela, pudemos vislumbrar outros horizontes de nossa própria aprendizagem e em aulas de matemática" (FRAGA, 2009, p. $56)$.

O 'abrir os horizontes' permite uma correlação entre conteúdos matemáticos com o real, algo essencial para a inserção nos primeiros anos do Ensino Fundamental, visto que são os pedagogos propiciam esse primeiro contato com a Matemática. Nesse sentido, é importante que esses profissionais tenham isso em mente e explorem conceitos básicos para a construção de significados.

Acredita-se que o papel da escola, nos primeiros anos, é aliar as vivências dos alunos com as práticas inseridas no ambiente escolar. Segundo Oliveira (2014),

\begin{abstract}
A exploração da linguagem da Geometria, ao longo da educação escolar, busca contribuir com a ampliação e sistematização dos conhecimentos já adquiridos pelo aluno em seu contexto social, levando-o à compreensão e à interpretação das situações propostas, utilizando-se de linguagens específicas para analisar, argumentar, avaliar, tomar decisões e realizar outras ações necessárias à sua formação (p. 25-26).
\end{abstract}

Contudo, ressalta-se que a falta de materiais didáticos nas escolas acarreta por prender os professores à formação inicial, a qual, por vezes, acaba não os preparando para a realidade e uso de tais recursos. Essa falta é um problema, mas pode haver saídas alternativas para tornar aulas dinâmicas e divertidas para os alunos. 
Ainda, para Oliveira (2014), o que distancia a Geometria das salas de aula dos Anos Iniciais é a necessidade que os professores sentem de ter um grande domínio dos conteúdos específicos da área, assim como a falta de suporte das instituições em que esses profissionais atuam no que diz respeito à construção de recursos pedagógicos. Deste modo, estes contrapontos contribuem para insegurança e falta de autonomia do professor, as quais são entendidas como basilares suportes básicos para o processo de ensino.

Deste modo, Oliveira (2014) aponta que é necessário o fortalecimento da pesquisa acadêmica sobre o tema, para que, assim, seja possível a promoção do estreitamento entre a prática nas escolas e a teoria.

Por fim, é importante que o professor não caia em um comodismo e não tenha medo de buscar soluções para os problemas enfrentados em sua prática, pois o que deve ser levado em consideração é o processo de aprendizagem dos alunos, de forma dinâmica, contextualizada e divertida, para que os mesmos se tornem preparados para a vida escolar e social.

\subsection{O QUE DIZEM ALGUMAS PUBLICAÇÕES SOBRE O TEMA}

A fim de identificar trabalhos existentes sobre a BNCC no tocante ao conteúdo de Geometria, realizamos um levantamento no catálogo de teses e dissertações da Capes e na Biblioteca Digital Brasileira de Teses e Dissertações (BDTD). Pelo fato da BNCC ter sido aprovada há pouco tempo, os trabalhos que abordam o tema são recentes, o que justifica o fato do número de publicações sobre o documento ser bastante escasso. Em síntese, foram encontradas três dissertações abordando a Geometria e a BNCC. Para a pesquisa, usou-se como descritores as palavras Geometria AND BNCC.

A primeira descoberta refere-se ao uso de um objeto de aprendizagem com o intuito de explorar conceitos geométricos relacionados à classificação de polígonos e área de figuras planas, pautados no conjunto de habilidades e competências prédefinidas nos Parâmetros Curriculares Nacionais - PCN e na BNCC, mais especificamente no que tange aos estudantes do $7^{\circ}$ ano do Ensino Fundamental. Neto (2017) avaliou um tipo de Objeto de Aprendizagem e identificou algumas contribuições deste para a apreensão de conceitos geométricos dos alunos. O autor fez um 
levantamento de temas matemáticos que podem ser abordados com o Tangram e as correspondentes possibilidades de uso desse recurso.

A segunda dissertação possui as seguintes perguntas geradoras: "alunos do $5^{\circ}$ ano do Ensino Fundamental da rede pública possuem conhecimentos adequados sobre os conteúdos de Geometria?"; "o recurso didático de uma HQ poderá possibilitar o desenvolvimento do pensamento geométrico de alunos dos Anos Iniciais do Ensino Fundamental?" (SOUZA, 2018, p. 23). Para a coleta de dados, foi usado um questionário fundamentado nos objetivos de aprendizagens dos PCN de 1997, assim como nos objetivos de conhecimentos descritos na $3^{\text {a }}$ versão da BNCC de 2017, dos Anos Iniciais do Ensino Fundamental, com foco nos conteúdos de figuras planas e tridimensional.

A terceira produção investigada teve como intenção analisar os conteúdos matemáticos ensinados nas escolas municipais do Rio de Janeiro e identificar possíveis reduções e/ou exclusões destes nos materiais pedagógicos utilizados em sala de aula. Para isso, Apolinário (2018) analisou as propostas da BNCC e as Orientações Curriculares da Secretaria Municipal de Educação do Rio de Janeiro (OCSME/RJ). Entre as questões norteadoras do estudo, destacamos a seguinte: Como o desenho geométrico pode contribuir para um melhor desempenho dos alunos na disciplina de Geometria e/ou em áreas diversas?

A fim de esclarecer os tópicos desenvolvidos, bem como os conteúdos referentes à Geometria, foi elaborado um quadro que ilustra as sínteses existentes nessas dissertações desenvolvidas e analisadas até esse presente momento (setembro de 2018). O Quadro 1 foi organizado levando em consideração o título, as palavras-chave do resumo, o público-alvoda pesquisa e o conteúdo ou conceito específico da Geometria.

Quadro 1 - Tópicos das dissertações encontradas.

Fonte: Elaborado pelos autores.

\begin{tabular}{|c|c|c|c|}
\hline Título da Dissertação & Palavras-chave & $\begin{array}{l}\text { Público- } \\
\text { alvo }\end{array}$ & $\begin{array}{l}\text { Conteúdo/ } \\
\text { conceito da } \\
\text { Geometria }\end{array}$ \\
\hline $\begin{array}{c}\text { TANGRAM TANGÍVEL } \\
\text { E A EXPLORAÇÃO DE } \\
\text { CONCEITOS EM } \\
\text { GEOMETRIA NO ENSINO }\end{array}$ & $\begin{array}{l}\text { Geometria. } \\
\text { Tangram. } \\
\text { Tecnologia. } \\
\text { Aprendizagem }\end{array}$ & $\begin{array}{l}\text { Alunos do } \\
7^{\circ} \text { ano do } \\
\text { Ensino } \\
\text { Fundamental }\end{array}$ & $\begin{array}{l}\text { Classificação de } \\
\text { polígonos e a área de } \\
\text { figuras planas }\end{array}$ \\
\hline
\end{tabular}




\begin{tabular}{|c|c|c|c|}
\hline FUNDAMENTAL & Significativa & & \\
\hline $\begin{array}{c}\text { O } \\
\text { DESENVOLVIMENTO DO } \\
\text { PENSAMENTO } \\
\text { GEOMÉTRICO: UMA } \\
\text { PROPOSTA DE RECURSO } \\
\text { DIDÁTICO POR MEIO DA } \\
\text { HQ. }\end{array}$ & $\begin{array}{c}\text { Pensamento } \\
\text { geométrico. } \\
\text { Educação } \\
\text { Matemática. Anos } \\
\text { Iniciais. Ensino } \\
\text { Fundamental. } \\
\text { História em } \\
\text { quadrinhos. }\end{array}$ & $\begin{array}{l}\text { Alunos do } \\
5^{\circ} \text { ano do } \\
\text { Ensino } \\
\text { Fundamental }\end{array}$ & $\begin{array}{l}\text { Pensamento } \\
\text { geométrico }\end{array}$ \\
\hline $\begin{array}{c}\text { ANÁLISE DOS } \\
\text { CONTEÚDOS } \\
\text { ABORDADOS NOS ANOS } \\
\text { FINAIS DO ENSINO } \\
\text { FUNDAMENTAL NO } \\
\text { MUNICÍPIO DO RIO DE } \\
\text { JANEIRO: O EXEMPLO } \\
\text { DO DESENHO } \\
\text { GEOMÉTRICO }\end{array}$ & $\begin{array}{c}\text { Currículo; } \\
\text { Conteúdos } \\
\text { Matemáticos; } \\
\text { Exclusão; } \\
\text { Redução; Desenho } \\
\text { Geométrico. }\end{array}$ & $\begin{array}{c}\text { Professores } \\
\text { da rede } \\
\text { municipal de } \\
\text { ensino }\end{array}$ & $\begin{array}{c}\text { Desenho } \\
\text { geométrico }\end{array}$ \\
\hline
\end{tabular}

Conforme ilustrado no Quadro 1, as produções existentes que abarcam os temas Geometria e BNCC levantam discussões com os professores sobre o currículo e propostas alternativas para o seu ensino, levando em consideração as habilidades e o que se espera esmiuçar de tal unidade temática. Essa breve busca de trabalhos existentes serviu como fonte para a escolha de referências teóricas e definição de um tema específico para os Anos Iniciais.

Optou-se pelo conteúdo de Geometria inserido no contexto dos Anos Iniciais do Ensino Fundamental, mais precisamente no quarto ano, em que se tem como objetos de conhecimento: localização e movimentação: pontos de referência, direção e sentido, paralelismo e perpendicularismo. No que se refere às habilidades esperadas de um aluno nessa unidade temática de Geometria, a BNCC (BRASIL, 2017) menciona que o estudante terá que:

(EF04MA16) Descrever deslocamentos e localização de pessoas e de objetos no espaço, por meio de malhas quadriculadas e representações como desenhos, mapas, planta baixa e croquis, empregando termos como direita e esquerda, mudanças de direção e sentido, intersecção, transversais, paralelas e perpendiculares. (p.290) 
Acreditou-se que atividade proposta na investigação vai ao encontro das habilidades propostas pelo documento, pois os alunos poderão se localizar e orientar no espaço tanto por meio da malha quadriculada, na qual será desenvolvido um jogo, quanto na atividade, que consiste em questões de localização, tendo como base a planta baixa de uma cidade.

\subsection{INVESTIGAÇÃO MATEMÁTICA}

Entendemos que um papel do professor é valorizar a participação do aluno no processo de aprendizagem, ou seja, torna-lo o principal sujeito deste processo. Em especial envolver os estudantes dos anos iniciais no processo parece indicar um caminho para uma boa iniciação científica em Geometria.

Atualmente, a maior preocupação dos educadores, nas aulas de Matemática, é motivar o aluno a ser o principal sujeito do seu processo de aprendizagem. Em turmas iniciais, o papel do professor é ainda mais complicado, pois o aluno está na fase embrionária da construção dos conceitos matemáticos, começando sua caminhada e buscando compreender o desconhecido.

Logo, para as atividades elaboradas para este trabalho, a metodologia da Investigação Matemática se mostra a mais viável, devido ao fato que a mesma, segundo Ponte, Brocardo e Oliveira (2003, p. 23), proporciona a mobilização de recursos cognitivos pelos alunos, tendo como finalidade atingir um objetivo específico. Para que isso ocorra, vale destacar, é importante o envolvimento dos alunos nas atividades, sendo esse o centro do processo e o professor um mediador das questões que podem surgir.

Ainda, para Ponte, Brocado e Oliveira (2003),

[...] investigar não é mais do que conhecer, procurar compreender, procurar encontrar soluções para os problemas com que nos deparamos. Trata-se de uma capacidade de primeira importância para todos os cidadãos e que deveria permear todo o trabalho da escola, tanto dos professores como dos alunos ( $\mathrm{p}$. 2).

Nesse sentido, o professor deve proporcionar ao aluno um ambiente de pesquisa e investigação, no qual os alunos venham a se envolver na busca de soluções e estratégias uma vez que essas devem partir das discussões realizadas na sala de aula de forma cooperativa com a intermediação do professor. 
Na Investigação Matemática, não se pode prever os resultados, pois o aluno deve pensar e buscar alternativas com base nas questões e atividades apresentadas pelo professor, de modo que passe a investigar. Autores como Tudella et al. (1999) recomendam que, para atividadesque envolvam um número elevado de alunos, sejam organizados gruposcom poucos membros, pois isso permite maior interação e discussão das atividades.

Ponte, Brocardo e Oliveira (2003, p. 23) ressaltam que essa metodologia pode ser organizada nas três etapas descritas a seguir.

- Introdução das atividades: consiste no momento em que o professor apresenta aos alunos a atividade que será transcorrida;

- Desenvolvimento da atividade: Neste momento, os alunos desenvolvem as atividades propostas pelo professor, buscando soluções para os problemas;

- Discussão da atividade: Os alunos discutem no grande grupo as ideias e soluções para as atividades, neste momento é feita a discussão e busca de alternativas em conjunto, buscando formular conceitos e certezas.

Dessa forma, desenvolveram-se algumas atividades com os seguintes propósitos: a) analisar como os alunos se comportariam diante delas; b) coletar os materiais utilizados e analisa-los após a aplicação. Com isso, esperava-se estimulá-los a pensar e interagir com os colegas, discutindo opiniões e aprendendo de forma coletiva.

\section{CAMINHOS METODOLÓGICOS}

A investigação realizada consiste em dois momentos: a) realização de duas atividades; b) aplicação do jogo intitulado ' $\mathrm{Na}$ Direção Certa'. A seguir, serão descritas essas duas etapas.

1) Tendo em vista a seguinte figura, vamos responder as atividades. 


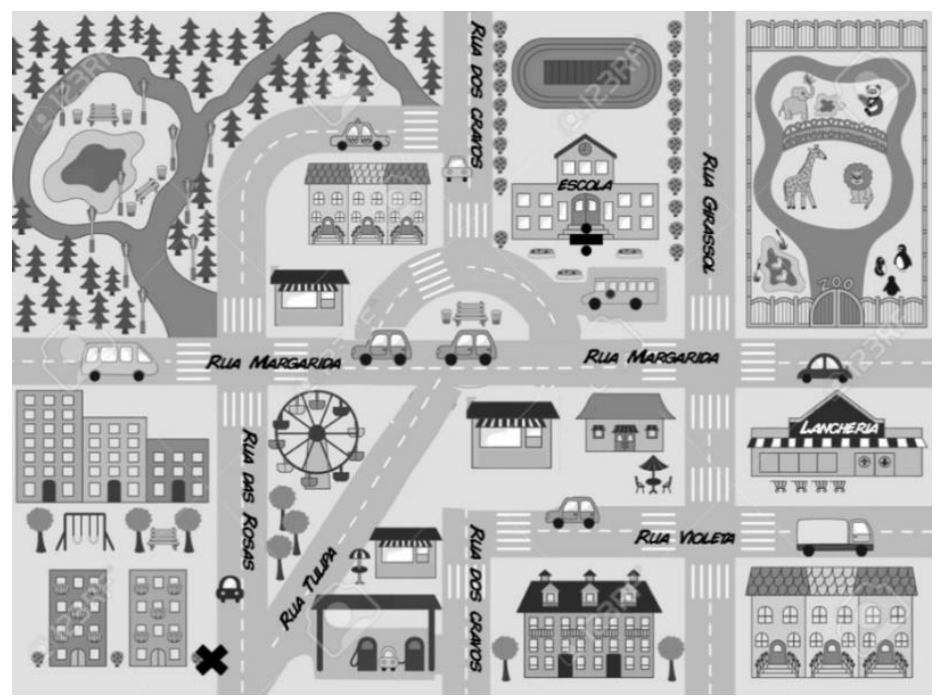

Figura 1 - Mapa da Cidade

Fonte: Elaborado pelos autores

a) Pedro mora no prédio Panambi, localizado com um " $\mathbf{x}$ " no mapa. Ele precisa chegar à escola localizada com o símbolo de divisão no mapa. Hoje, Pedro se atrasou e, por isso, perdeu o ônibus escolar, então teve de ir caminhando até ela.

- Quais os trajetos que Pedro poderá fazer a pé?

- Por quais ruas Pedro poderá passar?

- Qual é o menor trajeto mais provável que ele faria?

- E o maior trajeto, qual seria?

b) Usando o mesmo mapa, vamos descobrir qual é a casa de seu amigo Otávio.

São fornecidos os seguintes dados para resolver esse desafio:

- A casa do Otávio está na rua abaixo da Rua Margarida;

- Está à direita do posto de gasolina;

- Também está acima da Rua Violeta;

- Encontra-se à esquerda da Lancheria;

- Não é a do lado da roda gigante.

Marque a casa do Otávio com um "x". 
d) Será que na Rua Violeta, esquina com a Rua Girassol, eles irão se encontrar? Se sim, marque o lugar. Se não, dê uma explicação.

No segundo momento da investigação, foi utilizado o jogo: 'Na Direção Certa', presente na cartilha do Pacto Nacional pela Alfabetização na Idade Certa: JOGOS NA ALFABETIZAÇÃO no ensino de Matemática. (BRASIL, 2014) O objetivo do jogo consiste em construir noções de localização e movimentação no espaço físico para a orientação espacial em diferentes situações do cotidiano.

Com esse jogo, o aluno: a) utiliza noções topológicas; b) desenvolve a percepção de espaço; desloca o objeto em diferentes direções e distâncias; c) desenvolve lateralidade; reconhece quantidades; e d) faz contagens. As peças do jogo são as seguintes: um tabuleiro $11 \times 13$ (figura 2), marcadores representados por tampinhas de garrafa "pet"; um dado; cartões contendo as direções e sentidos segundo os quais os alunos vão se mover no tabuleiro (figura 3 ) e um envelope;

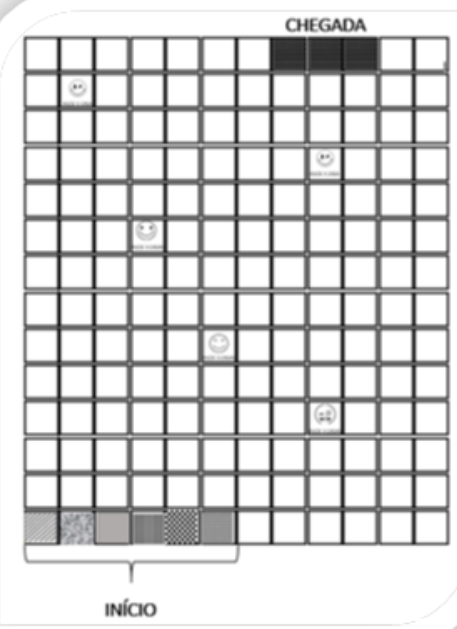

Figura 2 - Tabuleiro do Jogo.

Fonte: Adaptado Pacto Nacional pela alfabetização na idade certa

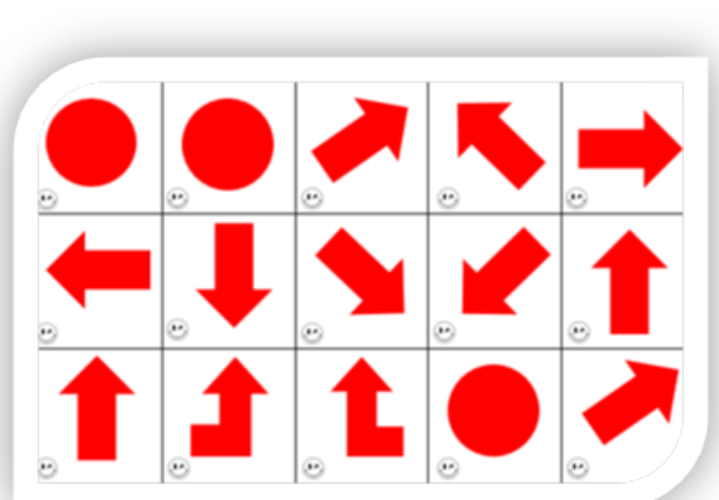

Figura 3 - Tabuleiro do Jogo.

Fonte: Adaptado Pacto Nacional pela alfabetização na idade certa

Regras do jogo.

- Colocam-se os marcadores no tabuleiro, nas posições de partida (quadrados cinza no material). O primeiro jogador escolhe a sua posição de partida. Da mesma forma, o $2^{\circ}$ jogador escolhe a sua posição, e assim sucessivamente. 
- Cada jogador, na sua vez, lança o dado e, logo após, retira uma carta do envelope, a qual indica a direção e o sentido que o jogador irá mover seu marcador no tabuleiro.

Podemos exemplificar com a seguinte jogada: se o jogador lança o dado, obtém como resultado o número 5 e saca do envelope o símbolo $\Rightarrow$, ele terá de andar com seu marcador 5 casas para a direita. Se não houver 5 casas para ele se deslocar, então o jogador deverá andar somente as casas disponíveis no momento. Se ele já estiver na última casa da coluna e não puder mais avançar, irá passar a sua vez de jogar. Outra situação interessante se dá quando, por exemplo, um jogador obtém, no lançamento do dado, o número 4, e seu símbolo retirado do envelope é _. Nessa ocasião, o jogador poderá optar pelos seguintes caminhos:

- 3 casas para a esquerda e 1 para cima;

- 1 casa para a direita e 3 para cima;

- 2 casas para a direita e 2 para cima;

Desse modo, o aluno terá três possibilidades de deslocamento na mesma jogada, cabendo a ele escolher e analisar o melhor caminho a seguir.

Se o jogador lançar o dado, retirar uma das setas do envelope e não puder realizar os comandos devido ao número de casas vazias para avançar, então ele perderá a sua vez no jogo.

Se o jogador cair em uma das casas especiais, deverá seguir o comando que estará descrito nela. Vence o jogo aquele que chegar primeiro na casa indicada como chegada.

Para melhor organização e registro das jogadas eatividades, os alunos irão receber uma tabela, na qual poderão registrar cada uma dessas ações. O Quadro 2 ilustra o modelo que será usado na atividade.

Quadro 2 - Organização e registro da atividade.

Fonte: Elaborado pelos autores.

\begin{tabular}{|l|l|l|l|l|l|l|}
\hline & Jogador 1 & Jogador 2 & Jogador 3 & Jogador 4 & Jogador 5 & Jogador 6 \\
\hline
\end{tabular}




\begin{tabular}{|l|l|l|l|l|l|l|}
\hline $1^{\circ}$ jogada & 4 para cima & 3 para baixo & & & & \\
\hline $2^{\circ}$ Jogada & & & & & & \\
\hline $3^{\circ}$ Jogada & & & & & & \\
\hline$\ldots$. & & & & & & \\
\hline
\end{tabular}

Nesta etapa, o registro é importante para o aluno observar as jogadas dos adversários e, dessa forma, criar estratégias para avançar e chegar ao final, concluindo a atividade.

\section{RESULTADOS E DISCUSSÕES}

Para análise dos resultados, optamos por fazer questão por questão, a fim de relacionar o que foi aprendido e desenvolvido na atividade com as habilidades descritas na BNCC. A pesquisa foi aplicada em uma turma de $4^{\circ}$ ano do Ensino Fundamental, em uma escola municipal da rede pública localizada na região central do estado do Rio Grande do Sul. Para a aplicação, contamos com a participação da professora regente e de um total de 15 alunos, variando na faixa etária de 10 a 13 anos.

Para a primeira questão, na qual foi apresentado o mapa da cidade, primeiramente foram localizadas, com o grande grupo, todas as ruas presentes nesse material. Depois disso, propomos questões norteadoras para trabalhar as noções de espaço e localização. Perguntamos aos alunos, primeiramente, quais eram os possíveis trajetos que Pedro poderia fazer para ir de sua casa até a escola. Assim, neste primeiro momento, cumpriuse a primeira etapa descrita na Investigação Matemática, a qual pontua a introdução das atividades a serem realizadas.

As respostas foram diversificadas, alguns alunos encontram 3 ou 4 trajetos, enquanto outros chegaram a marca de 7 trajetos. A figura 4 mostra a representação dessa situação em forma de desenho feito sobre o próprio mapa, pelo aluno A. 


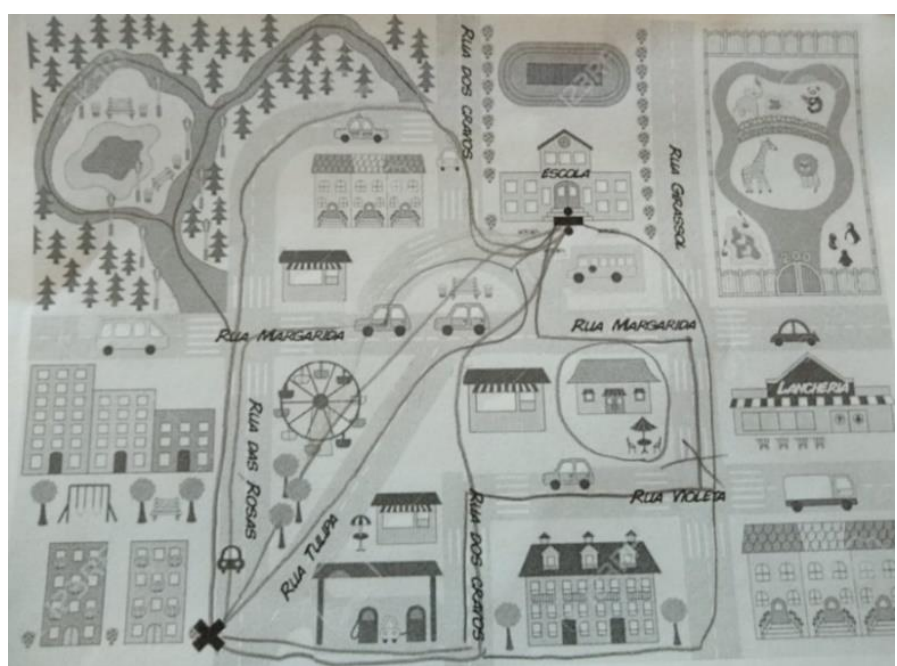

Figura 4 - Registro dos trajetos feitos pelo aluno A.

Fonte: Arquivos da Pesquisa.

Observando a representação feita, vemos que o aluno pensou em uma estratégia diferente, pois alegou que Pedro estaria caminhando e, como consequência, não precisaria usar somente os trajetos que continham ruas, ou seja, poderiam atravessar "dentro" do gramado de casas e estabelecimentos. Além disso, alguns alunos observaram que pegando caminhos diferentes, as distâncias seriam as mesmas, como, por exemplo, pela Rua Tulipa, na qual temos a possibilidade de andar pelos dois lados da rótula, percorrendo a mesma distância e chegando ao mesmo destino.

$\mathrm{Na}$ segunda questão, foi perguntado aos alunos por quais ruas Pedro poderia passar. Assim, os mesmos representaram e escreveram que Pedro poderia passar por todas as ruas do mapa, devido à diversidade de rotas (ruas e caminhos) dispostas na imagem encontradas.

Quanto ao menor trajeto percorrido, os alunos observaram seus próprios registros, concordando entre si que o trajeto pela Rua Tulipa, seguido da volta na rótula, tanto pela esquerda quanto pela direita, se concretizaria no menor, pois foi aquele com menor número de ruas percorridas. Já quando a pergunta se voltou para o maior trajeto, alguns alunos demonstraram dúvidas, pois havia dois caminhos de trajetórias extensas, logo se questionou qual seria o caminho mais longo? Como identificar o caminho mais longo?. A figura 5 ilustra o registro feito pelo aluno B com dois caminhos, demarcados com cores distintas. 


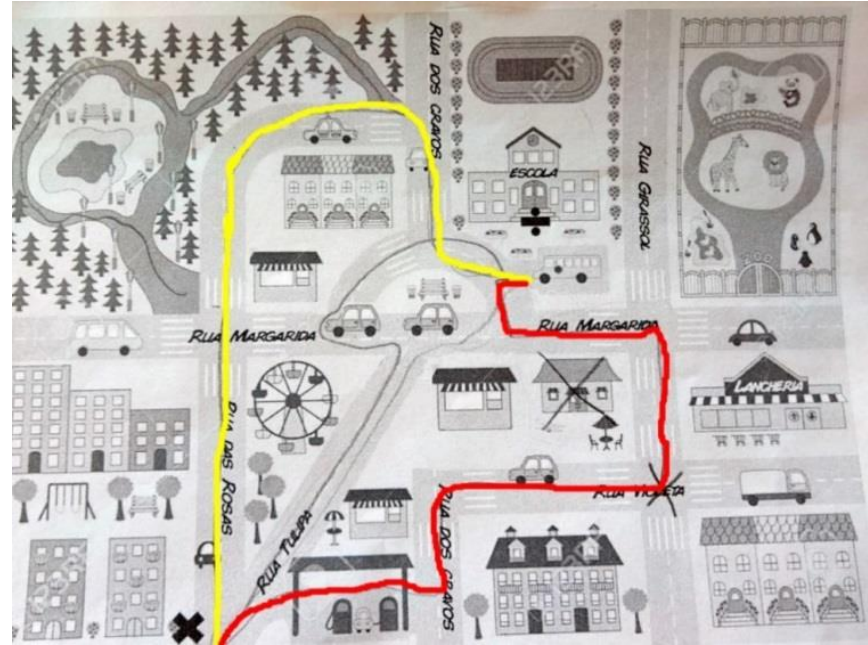

Figura 5 - Maiores Trajetos registrado pelo aluno B.

Fonte: Arquivos da Pesquisa.

Algumas orientações foram fornecidas aos alunos para que se descobrisse no mapa a casa de Otávio. Supreendentemente, os alunos, de forma unânime, encontraram a casa, sendo esta sinalizada com um $\mathrm{X}$ na figura 5 .

Posteriormente, quando questionados sobre o posicionamento de Pedro e Otávio, os alunos foram indagados a responder a seguinte questão: se caso Pedro estivesse na rua Margarida e Otávio na rua Violeta, eles iriam se encontrar? A figura 6 representa a resposta do aluno $\mathrm{C}$, o qual registrou o conceito de retas paralelas.

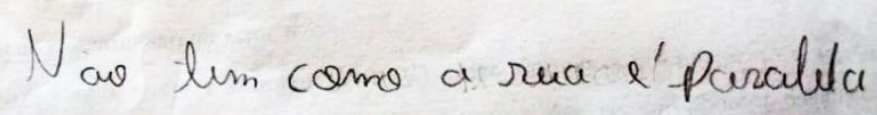

Figura 6 - Resposta do aluno C.

Fonte: Arquivos da Pesquisa.

As análises apresentadas até o momento para a resolução da atividade indicam que a segunda etapa da Investigação Matemática proposta por Ponte, Brocardo e Oliveira (2003) foi realizada, isto, “[...] os alunos desenvolvem as atividades propostas pelo professor, buscando soluções para os problemas [...]” (p. 23).

Ressalta-se, também, que neste momento as pesquisadoras, dialogando com os alunos, discutiram a importância da localização em atividades do cotidiano, dando-lhes a oportunidade de comentar sobre seus trajetos para chegar até a escola, bem como sobre a localização da rua de sua residência com relação às demais. 
No último questionamento desta atividade, os alunos foram provocados a responder outra situação: Será que na Rua Violeta, esquina com a Rua Girassol, eles vão se encontrar? Se sim, marque o lugar, se não dê uma explicação. Evidenciamos o trecho da resposta apontada pelo aluno D. A figura 7, demonstra essa descrição.

\section{4- SIM, PORQUL ESSAS RUAS SE CHAMAM PERPENTICULARES E POIS ISSO SE ENCONTRARAM NA LANCHERIA}

Figura 7 - Resposta do aluno D.

Fonte: Arquivos da Pesquisa.

Observamos, novamente, a presença de compreensão de conteúdos matemáticos, pois o aluno ressalta o conceito de retas perpendiculares e demarca com um $\mathrm{X}$ o ponto de intersecção. Dessa forma, entendemos que a terceira etapa da Investigação Matemática, foi contemplada de modo que os alunos discutiram os aspectos da atividade a todo o momento como a interferência dos investigadores, promovendo discussões e outras indagações sobre a mesma situação.

A segunda atividade consistiu na aplicação do jogo "Na Direção Certa". Como indica a metodologia da Investigação Matemática, o material foi apresentado aos alunos, os quais foram separados em quatro grupos, três com quatro integrantes e um com três integrantes. As regras do jogo, bem como as possíveis estratégias, foram explicitadas pelas pesquisadoras antes da aplicação, para uma rodada teste. Os alunos foram orientados a registrar os movimentos e quantidades de casas que cada jogador iria percorrer na malha quadriculada. No que segue se ilustra (Figura 8) uma representação do desenvolvimento da atividade, a qual corresponde à segunda etapa da metodologia empregada, a qual retrata o registro de dois grupos e suas respectivas jogadas.

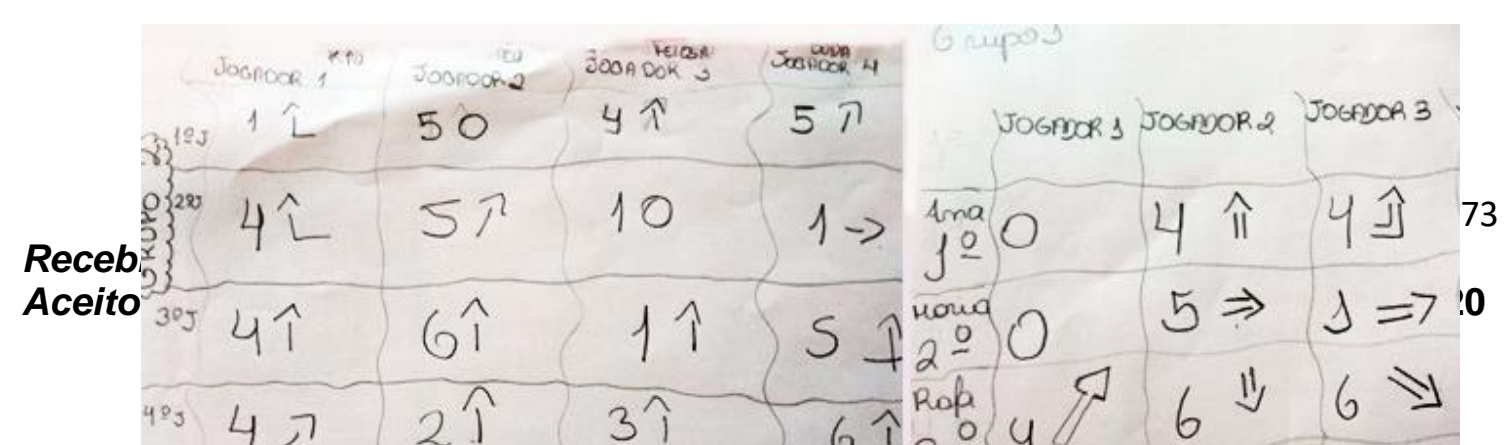


Figura 8 - Registro do Grupos.

Fonte: Arquivos da Pesquisa.

No que diz respeito à terceira etapa da Investigação Matemática, foi observado os registros e as falas dos alunos no momento da aplicação, percebendo surgirem conceitos como diagonal, vertical, horizontal, intersecção, transversais e paralelas. Vale ressaltar que os alunos reconheciam as movimentações, ainda que não utilizassem termos formais da Matemática. Nesse sentido, vemos como um ponto positivo o reconhecimento de movimentações no plano e a motivação dos discentes para estudar e se divertir usando o material.

Miorim e Fiorentini (1990, p. 7) abordam a importância do ensino contextualizado, ressaltando a inserção do jogo no processo de aprendizagem do aluno, o qual "pode vir no início de um novo conteúdo com a finalidade de despertar o interesse da criança ou no final com o intuito de fixar a aprendizagem e reforçar o desenvolvimento de atitudes e habilidades".

Acreditamos que as atividades propostas foram diversificadas a ponto de promover a participação ativa dos alunos, bem como a construção e fortalecimento de conteúdos do eixo Geometria, o qual a BNCC aborda como um dos tópicos a serem tratados por professores do $4^{\circ}$ ano do Ensino Fundamental.

\section{CONCLUSÃO}


Observamos, quando trabalhamos com um público diversificado, que as estratégias também devem ser diversificadas. Logo, como a presente atividade voltou-se para os Anos Iniciais do Ensino Fundamental, os pesquisadores buscaram métodos específicos para desenvolver conteúdos de Geometria adequados ao nível em apreço, como o uso de jogos e mapas.

Pensando na BNCC, ressaltamos que a habilidade descrita para o $4^{\circ}$ ano do Ensino Fundamental foi contemplada, uma vez que os resultados obtidos permitiram examinar estratégias e métodos para solucionar as questões fornecidas no mapa, a exemplo dos trajetos a pé e dos trajetos de ônibus. Essas questões, por vezes, foram solucionadas de formas distintas, tanto por meio da escrita quanto através de desenhos.

A metodologia de Investigação Matemática permitiu maior abrangência de respostas, devido ao fato de que esta é uma alternativa que proporciona aos alunos momentos de reflexão e busca por estratégias. Os pesquisadores, mediadores das atividades, tornaram a investigação um processo de construção de significados, levando em consideração o objetivoinicial da pesquisa: explorar percepção, visualização e construção de conhecimentos geométricos por meio de atividades lúdicas voltadas para o $4^{\circ}$ ano do Ensino Fundamental. Portanto, entendemos que a pesquisa realizada e analisada se caracteriza como qualitativa em ensino (MOREIRA, 2011).

Assim, no intuito de explorar percepção, visualização e construção de conhecimentos geométricos por meio de atividades lúdicas voltadas ao $4^{\circ}$ ano do Ensino Fundamental fossem surgindo novas dúvidas a serem discutidas em sala de aula, permitindo assim o desenvolvimento da criatividade e da autonomia desses estudantes. Com isso, a partir da percepção visual, principalmente, a construção do conhecimento geométrico dos investigados parece ter ocorrido.

Além disso, os pressupostos indicados pela BNCC parecem ter sido contemplados com as atividades envolvendo a Investigação Matemática, uma vez que estudantes descreveram deslocamentos, por meio de um mapa, localizando pontos específicos como casas, lanchonetes, ruas etc. No croqui fornecido, os estudantes exploraram conceitos de forma involuntária, como é o caso de retas paralelas e perpendiculares, sem a interferência dos pesquisadores. Tais conceitos ainda não haviam sido desenvolvidos em sala de aula. 
Dessa forma, as atividades podem ser vistas como uma alternativa para subsidiar o trabalho dos professores, visto que as mesmas se tratam de possíveis estratégias serem aplicada, devido ao baixo custo de produção. Além disso, esse tipo de atividade ajuda a fortalecer a inserção da pesquisa acadêmica nas escolas, buscando caminhos para o melhoramento do Ensino Básico no Brasil.

\section{REFERÊNCIAS}

APOLINÁRIO, H. L. Analise dos conteúdos abordados nos anos finais do Ensino Fundamental no município do Rio de Janeiro: O exemplo do Desenho Geométrico. 2018. 121 f. Dissertação (Programa de Pós-Graduação em Ensino de Matemática). Universidade Federal do Rio de Janeiro. Rio de Janeiro.

BRASIL. Base Nacional Comum Curricular (BNCC). Consulta Pública. Matemática. MEC/ Undime/ Consed, $3^{\mathrm{a}}$ v. 2017.

BRASIL. Pacto Nacional pela alfabetização da idade certa: jogos na alfabetização matemática-geometria/ministério da educação, Secretaria de Educação básica, Diretoria de apoio a gestão educacional. Brasília: MEC, SEB, 2014.

\section{BRASIL. MINISTÉRIO DA EDUCAÇÃO. SECRETARIA DE EDUCAÇÃO BÁSICA. Base Nacional Comum Curricular. Brasília, 2006.}

FRAGA, S. A. S. Aprendizagens de professoras num grupo de estudos sobre matemática nas séries iniciais. 2009. 364 f. Tese (Programa de Pós-Graduação em Educação) - Centro de Educação, Universidade Federal do Espírito Santo, Vitória, 2009.

LORENZATO, S. Porque não ensinar Geometria? Educação Matemática em Revista. v. 3, n. 4, p. 3-13, 1995

MIORIM, M. A., FIORENTINI, D. Uma reflexão sobre o uso de materiais concretos e jogos no Ensino da Matemática. Boletim da SBEM-SP, São Paulo, v. 4, n. 7, p. 5-10, 1990.

MOREIRA, M.A. Metodologias de Pesquisa em Ensino. São Paulo: Editora Livraria da Física, 2011.

NETO, A.F.M.Tangram Tangível e a exploração de conceitos em Geometria no Ensino Fundamental. 2017. 138 f. Dissertação (Programa de Pós-Graduação em Ensino de Ciências e Matemática). Departamento de Física. Instituto de Ciências Exatas. Universidade Federal do Amazonas.

OLIVEIRA, R. C. Investigando o Ensino de Geometria nos Anos Inicias do Ensino Fundamental: uma análise das escolhas dos professores. Dissertação (Mestrado em 
Educação Matemática e Tecnológica) - Universidade Federal de Pernambuco, Recife, 2014.

PONTE, J. P.; BROCADO, J.; OLIVEIRA, H. Investigações matemáticas na sala de aula. Belo Horizonte: Autêntica Editora, 2003.

SOUZA, P. P. F. C. O desenvolvimento do pensamento geométrico: uma proposta de recurso didático por meio da HQ. 2018. 131f. Dissertação (Mestrado em Docência na Educação Básica) - Faculdade de Ciências, UNESP, Bauru SP, 2018.

TUDELLA, A. FERREIRA, C.; BERNARDO, C.; PIRES, F.; FONSECA, H.; SEGURADO, I.; VARANDAS, J. Dinâmica de uma aula com investigação. In ABRANTES, P. et al. Investigações Matemáticas na aula e no currículo. Lisboa: CRL, 1999, p. 87-96. 